\title{
EXPERIMENTS ON ICE RIDE-UP AND PILE-UP
}

by

\author{
D. S. Sodhi, K. Hirayama*, F. D. Haynes and K. Kato** \\ (U.S. Army Cold Regions Research and Engineering Laboratory, 72 Lyme Road, Hanover, New \\ Hampshire 03755, U.S.A.)
}

\section{ABSTRACT}

Ice pile-up and ride-up are common occurrences along beaches in the sub-Arctic and Arctic. An understanding of the factors which lead to pile-up is important for design of a defensive strategy to prevent damage to coastal installations.

Since ice action on a sloping beach is complex, an experimental model study was undertaken to determine the factors which promote ice pile-up. The factors varied in this study were the freeboard, slope, and roughness of the beach. One experiment was performed to observe the effectiveness of a shore defense structure against ice ride-up.

\section{INTRODUCTION}

Under the influence of environmental forces, sea ice in the polar regions sometimes forms shore pile-ups. At other times ice rides up and slides inland as much as $100 \mathrm{~m}$, causing damage to trees and coastal installations. Kovacs and Sodhi (1980) have published a review of the literature on ice pile-up and ride-up in Arctic and sub-Arctic waters, along with an account of their own observations.

In the last decade, many artificial islands have been constructed for the exploration of hydrocarbon resources in the Beaufort Sea. Most of these islands have been located in shallow water, where the movements in the fast-ice zone are generally not excessive. But the islands constructed farther offshore may be susceptible to damage by ice encroachment. Clearly, the design of artificial islands should incorporate features which will help the formation of an ice pileup (Croasdale and others 1973, Vaudrey and Potter 1981). Once a pile-up is formed, the rubble field around the island tends to protect shore installations by creating a barrier to further ice encroachment. However, the initial pile-up can also function as a ramp and allow ice behind it to climb up very steep embankments.

Since the ice action on a sloping beach is complex, an experimental study was undertaken to determine the factors which promote an ice pile-up. The factors varied in this study were the freeboard, slope and roughness of the beach. The flexural strength and the characteristic length of each ice sheet were determined before each experiment. One experiment was performed to determine the effectiveness of a shore defense structure against ice ride-up. In this paper, a description of the experimental setup and observations made during the experiments are reported. The results are presented in the form of occurrence of a pile-up or a ride-up.

The other experimental studies of this kind, known to the authors, were done by Abdelnour and Edwards (1976) and Semeniuk (1977). In those studies, the objectives of the model tests were to provide data on the ice ride-up and pile-up phenomena and to develop a predictive model to assess the risk that this ice behavior poses for artificial islands in the Beaufort Sea.

\section{EXPERIMENTS}

The experimental set-up, shown schemetically in Figure 1, consisted of three steel frames, each $1.83 \mathrm{~m}$ wide and supported on three pins. Wooden structures were attached to the steel frame so that the parameters of the beach, i.e. freeboard, slope and roughness, could be changed for different experiments. The model beaches are shown in Figures 2 to 9 and their dimensions are listed in Table I.

A force-measuring system was incorporated in the beach by the use of instrumented pins. Shortly after installation, the underwater pins developed leaks, resulting in their malfunction, while the above-water pins worked well. The normal reaction force could be used to determine the ice force if its point of action and direction were known. Later, two instrumented rods were attached to the carriage to obtain the horizontal forces required to push the ice sheet. The ice-force data are not presented in this paper as they are still not correlated with events taking place during the ice action on the beach.

The ice sheets were grown by seeding and freezing a $1 \%$ urea-in-water solution at an ambient temperature of $-12^{\circ} \mathrm{C}$. The texture of the resulting ice sheet may be described as columnar. The flexural strength and characteristic length of each ice sheet were determined before each experiment; the values are given

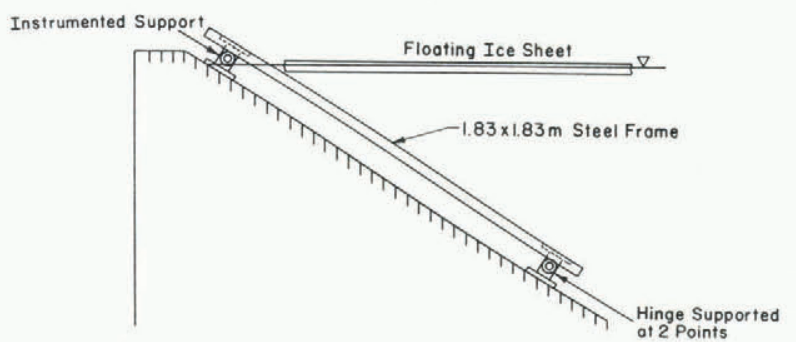

Fig.1. Sketch of steel frame $1.83 \mathrm{~m}$ wide.

* Visiting Professor, Iwate University, Iwate, Japan.

**Visiting Research Engineer, Ishikawajimi-Harima Heavy Industries Co. Ltd., Tokyo, Japan. 
TABLE I. ICE PROPERTIES, BEACH PARAMETERS AND EXPERIMENTAL RESULTS

\begin{tabular}{|c|c|c|c|}
\hline Experiment & $\begin{array}{c}\text { Ice } \\
\text { thickness } \\
h(\mathrm{~cm})\end{array}$ & $\begin{array}{c}\text { Characteristic } \\
\text { length } \\
\mathrm{L}(\mathrm{cm})\end{array}$ & $\begin{array}{l}\text { Flexur } \\
\text { strengt } \\
\sigma_{f}(k P c\end{array}$ \\
\hline 1 & 3.6 & 29 & 50 \\
\hline 2 & 3.6 & 29 & 50 \\
\hline 3 & 4.3 & 46 & 45 \\
\hline 4 & 5.8 & 54 & 53 \\
\hline 5 & 6.0 & 51 & 25 \\
\hline 6 & 3.5 & 25 & 25 \\
\hline 7 & 3.5 & 25 & 25 \\
\hline 8 & 3.3 & 45 & 65 \\
\hline $9 *$ & 3.3 & 45 & 65 \\
\hline 10 & 3.3 & 45 & 65 \\
\hline 11 & 4.8 & 56 & 29 \\
\hline 12 & 2.7 & 27 & 37 \\
\hline 13 & 5.8 & 55 & 32 \\
\hline 14 & 2.2 & 25 & 60 \\
\hline 15 & 2.2 & 38 & 102 \\
\hline 16 & 3.0 & 38 & 40 \\
\hline 17 & 3.4 & 45 & 100 \\
\hline 18 & 2.8 & 39 & 90 \\
\hline 19 & 3.6 & 43 & 74 \\
\hline 20 & 2.8 & 39 & 90 \\
\hline 21 & 2.8 & 39 & 90 \\
\hline 22 & 3.6 & 48 & 103 \\
\hline 23 & 3.6 & 48 & 103 \\
\hline 24 & 2.9 & 38 & 60 \\
\hline 25 & 3.4 & 46 & 78 \\
\hline 26 & 2.8 & 32 & 39 \\
\hline 27 & 2.8 & 32 & 39 \\
\hline 28 & 3.0 & 33 & 50 \\
\hline 29 & 3.1 & 32 & 41 \\
\hline 30 & 5.9 & 60 & 55 \\
\hline 31 & 5.9 & 60 & 55 \\
\hline 32 & 3.8 & 35 & 46 \\
\hline 33 & 3.8 & 35 & 46 \\
\hline 34 & 4.3 & 45 & 51 \\
\hline 35 & 4.3 & 45 & 51 \\
\hline
\end{tabular}

in Table I. The ice sheets were pushed at constant speeds, which are also listed in Table I. The experiments were photographed and recorded on video tape.

\section{RESULTS}

An account of the observations made during each experiment is given below.

\section{Experiments 1 and 2}

The ice sheet was pushed against the sloping beach shown in Figure 2 at speeds of 2.3 and

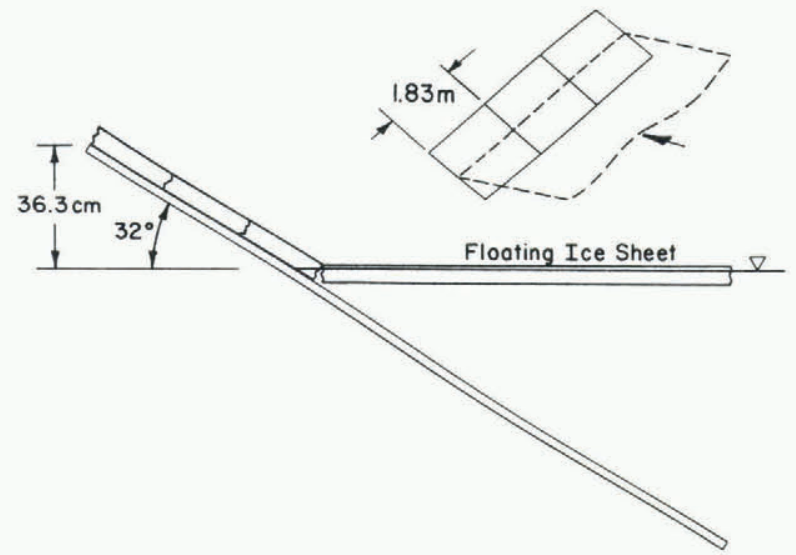

Fig.2. Sketch showing the freeboard and slope of the beach used in experiments $1,2,7$ and 8 .

$\begin{array}{cccc}\text { Velocity } & & \text { Result (pile- } \\ \text { of ice } & \text { Freeboard } & \text { Slope } & \text { up P or ride- } \\ v_{f}\left(\mathrm{~cm} \mathrm{~s}^{-1}\right) & H(\mathrm{~cm}) & (\alpha) & \text { up R) }\end{array}$

$\begin{array}{lll}2.3 & 36 & 32^{\circ} \\ 6.0 & 36 & 32^{\circ} \\ 2.5 & 36 & 32^{\circ} \\ 2.0 & 36 & 32^{\circ} \\ 2.5 & 43 & 23^{\circ} \\ 1.9 & 55 & 42^{\circ} \\ 1.9 & 36 & 32^{\circ} \\ 2.0 & 36 & 32^{\circ} \\ 2.0 & 60 & 42^{\circ} \\ 2.0 & 63 & 35^{\circ} \\ 3.0 & 61 & 42^{\circ} \\ 3.0 & 61 & 32^{\circ} \\ 3.0 & 50 & 32^{\circ} \\ 3.0 & 47 & 22^{\circ} \\ 3.0 & 32 & 32^{\circ} \\ 2.5 & 52 & 32^{\circ} \\ 2.5 & 52 & 32^{\circ} \\ 2.5 & 50 & 22^{\circ} \\ 2.5 & 61 & 22^{\circ} \\ 2.5 & 46 & 32^{\circ} \\ 2.5 & 46 & 42^{\circ} \\ 2.5 & 40 & 32^{\circ} \\ 2.5 & 40 & 42^{\circ} \\ 2.5 & 68 & 22^{\circ} \\ 2.5 & 60 & 22^{\circ} \\ 2.5 & 44 & 32^{\circ} \\ 2.5 & 44 & 42^{\circ} \\ 2.5 & 48 & 32^{\circ} \\ 2.5 & 48 & 42^{\circ} \\ 2.5 & 68 & 32^{\circ} \\ 2.5 & 68 & 42^{\circ} \\ 2.5 & 64 & 32^{\circ} \\ 2.5 & 64 & 42^{\circ} \\ 2.5 & 69 & 32^{\circ} \\ 2.5 & 42^{\circ}\end{array}$

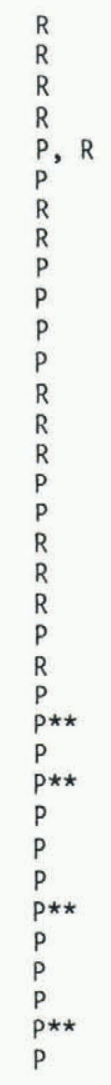

$6.0 \mathrm{~cm} \mathrm{~s}^{-1}$. It broke into blocks as it rode up the sloping surface. Although a pile-up occurred on the left-hand side of the beach, it had started to form outside the beach area due to interference of ice with a deflector plate which was installed to protect the instrumentation cable. Therefore, the outcome of the experiments is said to be an occurrence of ice ride-up.

Experiments 3 and 4

The objective of these two experiments was to observe the effect of uneven beach slope and the

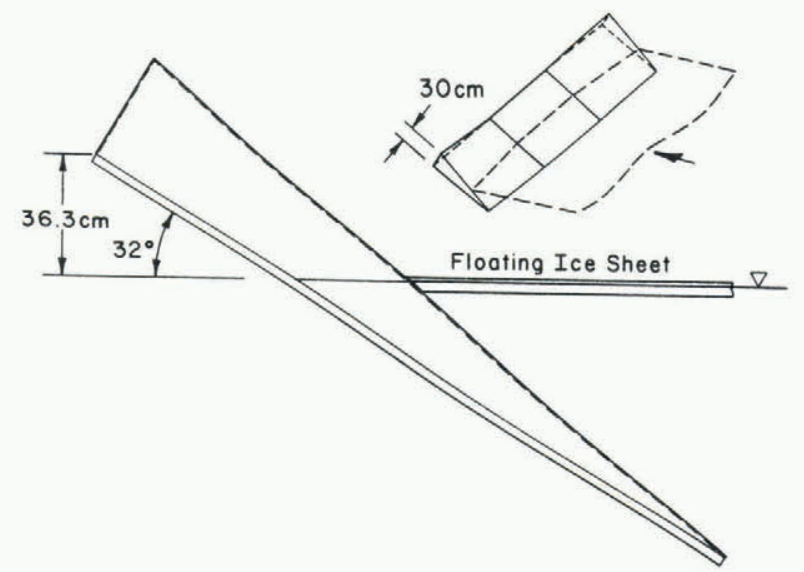

Fig.3. Sketch of the beach with uneven slope (experiment 3).

* Shore defense structures were used.

** Pile-up on rough segment and some ride-up on smooth segments. 


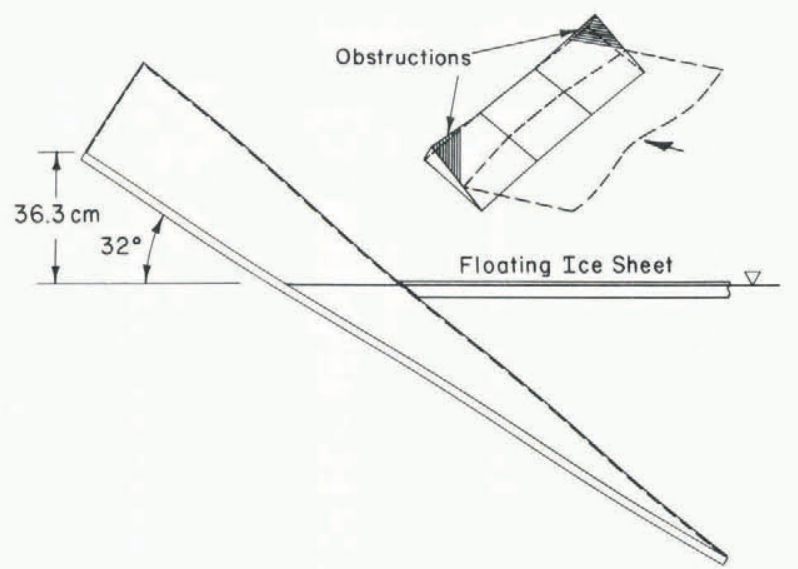

Fig.4. Sketch of the beach with uneven slope and obstructions (experiment 4).

presence of obstructions such as boulders or other structures. The configuration of the beach, shown in Figures 3 and 4 , was changed from that in experiments 1 and 2 . In experiment 4 , the ice sheet started to ride up and then slid back after encountering resistance from large obstructions. The ice sheet also failed many times due to buckling. The rubble formed during this failure sank, and there appeared to be no pile-up above the water. The loss of rubble under the water resulted in a ride-up. Thus it was concluded that the profile of the sea floor should be incorporated in order to prevent the rubble from submerging.

Experiment 5

From the experience gained in previous experiments, an underwater ledge was incorporated, as shown in Figure 5. The left-hand segment of the beach was made rough by nailing triangular wooden pieces to the structure. At first, the ice sheet rode up on all three segments. Then it buckled and formed rubble on the rough end of the beach. After some time, a sheet of ice lodged on the rough surface. Subsequently, the ice rode up over this and there was flooding on top of the ice sheet at the lower end of the beach. It is believed that the shallow underwater ledge (10 cm below water level) prevented the ice sheet from submerging further, as had happened many times during previous experiments. The outcome of this experiment was a pile-up in the beginning and then a ride-up towards the end of the experiment. Experiment 6

The profile of the beach is sketched in Figure 6 . All three segments of the beach were smooth, and the

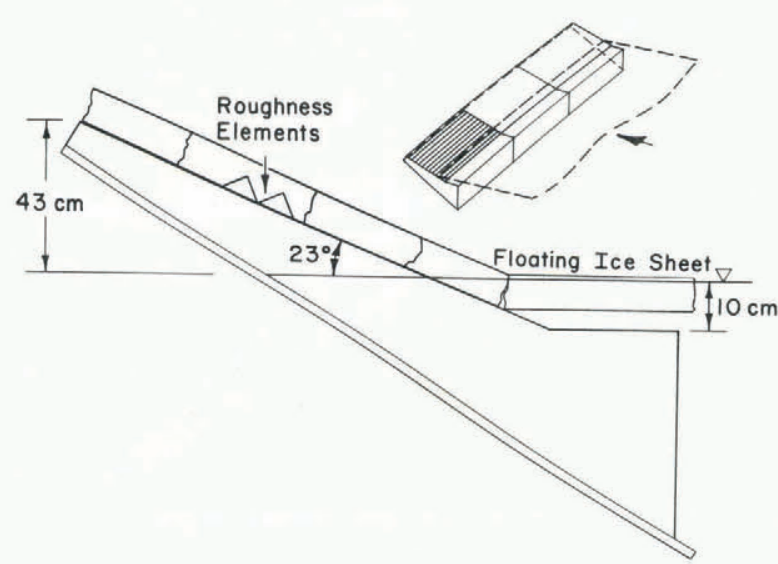

Fig.5. Sketch of the beach used in experiment 5 . The left segment of the beach is made rough by triangular wooden pieces.

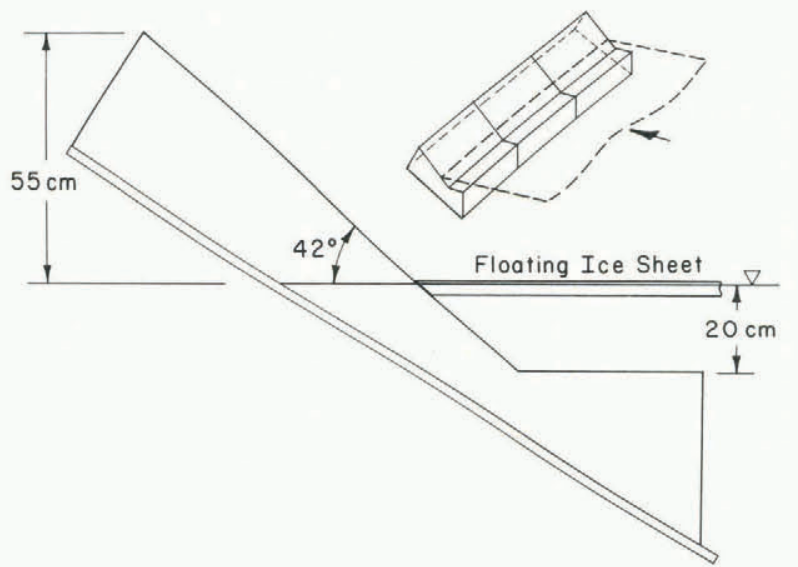

Fig.6. Sketch of the beach used in experiment 6 .

underwater ledge was $25 \mathrm{~cm}$ below the surface. After a small initial ride-up, the ice slid back, buckled, and formed rubble from the beginning to the end of the experiment. There were many instances of buckling taking place in small and large areas of the ice sheet. Similar observations have been reported by Gladwell (1977) during ice action against a rubble field around the artificial island Netserk F40. The ice sheet was observed to move forward with a jerking motion. This is believed to be caused by the flexibility of the ice sheet and not by the carriage, which was observed to move at a constant speed. The outcome of this experiment was an ice pile-up. Experiment 7

The ice sheet used was the same as in the previous experiment, and the beach geometry was the same as in experiment 1 (Fig.2). The ice sheet rode up the inclined surface and there was no pile-up. Experiment 8

The beach geometry was the same as in experiment 1 (Fig.2), and a new ice sheet was used, which rode up the inclined surface. This and the previous experiment were conducted to confirm the ice ride-up for the same beach geometry but for different ice properties. Experiment 9

In this experiment, four shore defense structures were placed at spacings of $1.83 \mathrm{~m}$, as shown in Figure 7 . These structures were similar to those proposed by Vaudrey and Potter (1981) and the objective was to observe their effectiveness. The ice rode up

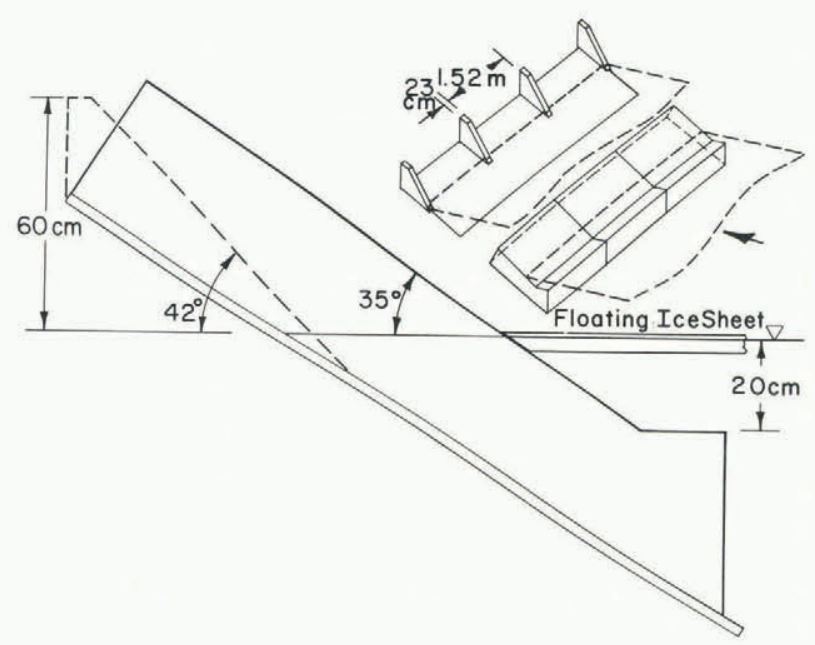

Fig.7. Sketch showing the shore defense structure used in experiment 9 and the beach used in experiment 10 . 
on the structures, failed in bending, and started to form a pile-up. Further interaction of the ice sheet with rubble ice resulted in buckling failure. The outcome was an ice pile-up. Experiment 10

The profile of the beach for this experiment is shown in Figure 7 . The same ice sheet was used as in the previous two experiments. The observations made were the same as those for experiment 6 . An ice pile-up formed at the end of this experiment. Experiments 11 to 35

After gaining experience from the previous ten experiments, it was decided that a set of experiments should be performed in which the beach parameters (freeboard, slope and roughness) would be changed. The beach profiles used in experiments 11 and 12 are shown in Figures 8 and 9, respectively. As these profiles are typical, the other beach profiles are not sketched. During this set of experiments, the lefthand segment of the beach was made rough by nailing on triangular wooden bars as shown in Figures 5,8 and 9. The other two segments of the beach were smooth. This was done to observe any difference between the effects of smooth and rough surfaces of the beach. The values of the freeboard and the slope of beach profiles are given in Table I along with the thickness and properties of the ice sheet used in these experiments. The outcome of each experiment is also listed in Table $I$ in terms of ice pile-up $(P)$ or ride-up $(R)$.

In the case of an ice ride-up, the ice sheet failed by bending into blocks and rode up the beach. But an ice pile-up was preceded by an initial ride-up until the ice sheet either fell back or lodged itself on the beach. Occasionally, the ice sheet buckled

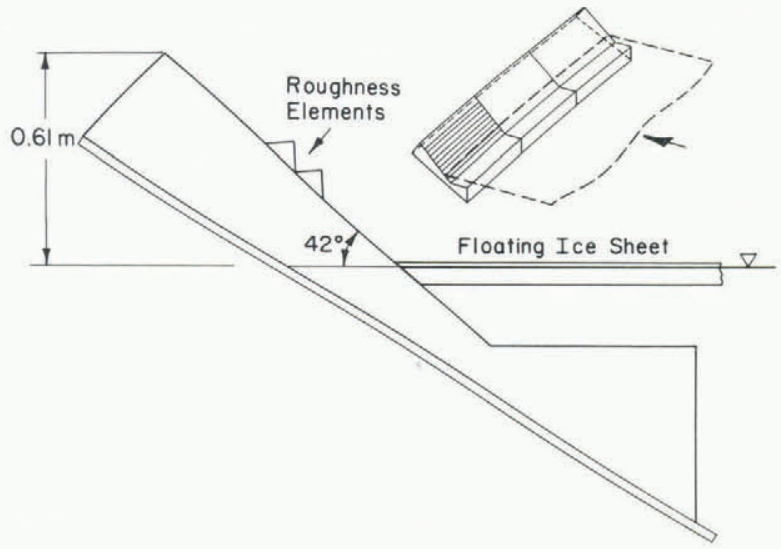

Fig.8. Sketch of the beach used in experiment 11 . The left segment of the beach is rough.

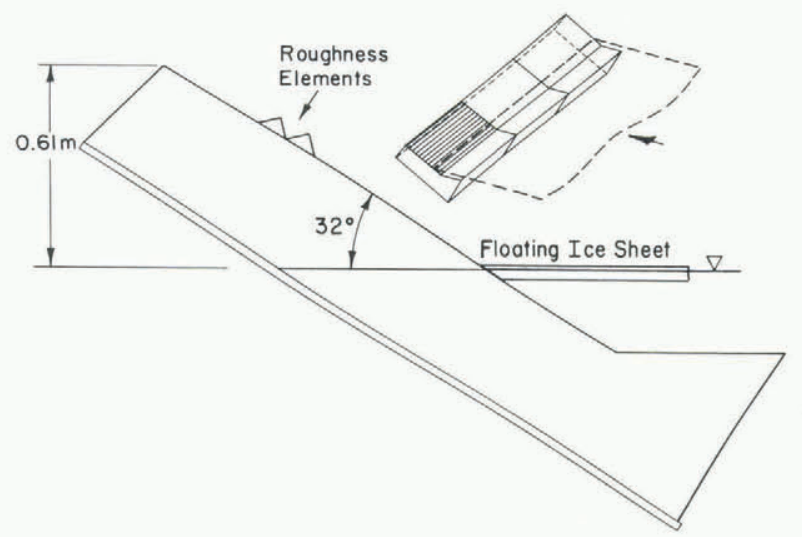

Fig.9. Sketch of the beach used in experiment 12 . The left segment of the beach is rough.

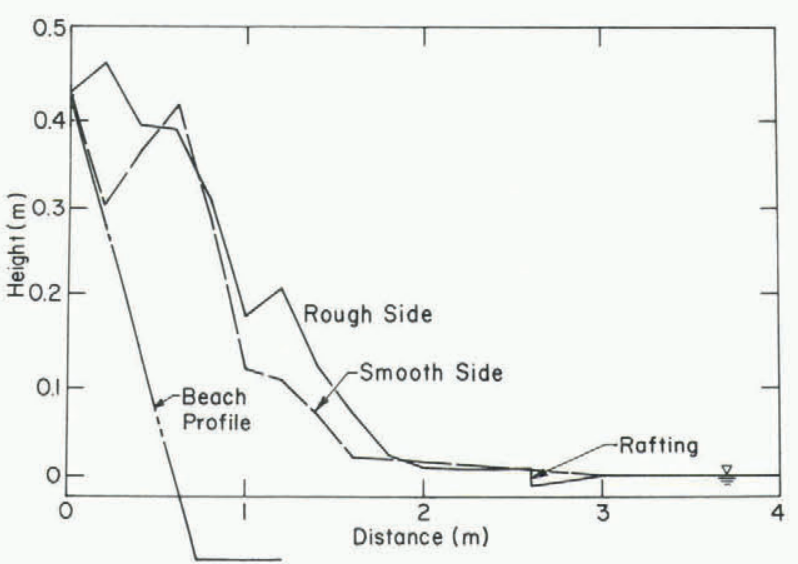

Fig.10. Profiles of the ice pile-up in experiment 12 .

across part of or the whole of the width of the beach. During the above processes, there was formation of rubble at the beach. Sometimes, the ice sheet would ride up on top of the rubble formed in an ice pile-up. The outcome of the experiments listed in Table I corresponds to the development of a steady-state situation after considerable $(>10 \mathrm{~m})$ movement of the ice sheet.

Figure 10 shows profiles of an ice pile-up in experiment 12 along two lines in the middle of the rough and smooth segments of the beach. A general observation can be made on the effects of beach surface that the ice sheet started to form a pile-up on the rough segment of the beach earlier than on the smooth segment. Once pile-up developed, there

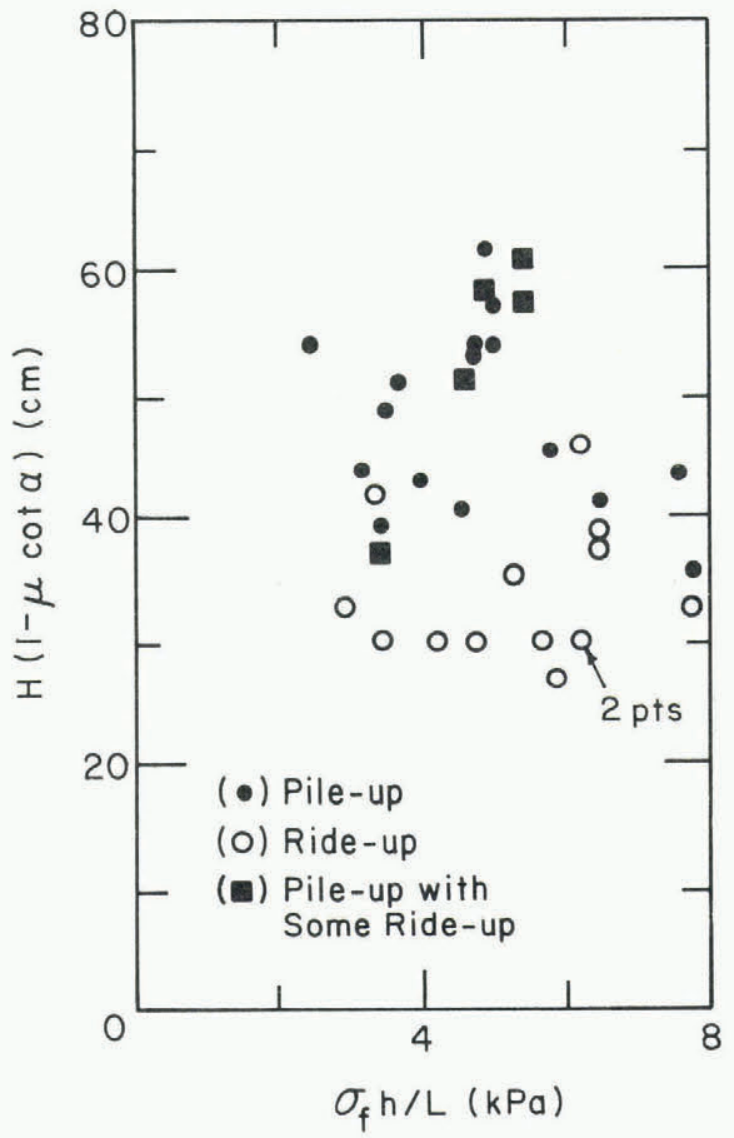

Fig.11. Plot of $H(1-\mu \cot \alpha)$ with respect to $\sigma_{f} h / L$. 
was very little difference in the ice action or the profiles of the pile-up formed on the rough and smooth segments of the beach.

\section{DISCUSSION}

During the experiments which resulted in ice pileups, the ice sheet slid back and buckled many times. In an attempt to group the occurrences of pile-up and ride-up, it seems logical to plot some parameters of the beach with respect to those of the ice sheet.

The ice force required to push an ice sheet which will overcome gravitational and frictional forces may be said to be proportional to the weight of the ice sheet on the beach (Kovacs and Sodhi 1980), and this force per unit width is proportional to $H h(1+\mu \cot \alpha)$, where $H$ is the freeboard, $\alpha$ the slope angle, $\mu$ the coefficient of friction and $h$ the ice thickness. However, the force per unit width is proportional to $H h(1-\mu \cot \alpha)$ if the ice sheet on the beach is sliding down and pushing the floating ice down.

The force per unit width required to fail an ice sheet in bending is proportional to $\sigma_{f} h^{2} / L$ (Croasdale and others 1978), where of is the flexural strength and $L$ the characteristic length of the ice sheet. In Figure $11, H(1-\mu \cot \alpha)$ is plotted with respect to $\sigma_{f} h / L$ with dark circles for pile-ups and open circles for ride-ups as indication of the outcome of an experiment. The coefficient of friction $\mu$ between ice and plywood was measured to be 0.09 (Haynes and others 1982). There is no estimate of $\mu$ for the rough segment of the beach.

The force per unit width required to fail an ice sheet in buckling is proportional to $L^{2}$ (Sodhi 1979). In Figure 12, $H(1+\mu \cot \alpha)$ is plotted with respect to $L^{2} / h$, as in Figure 11 .

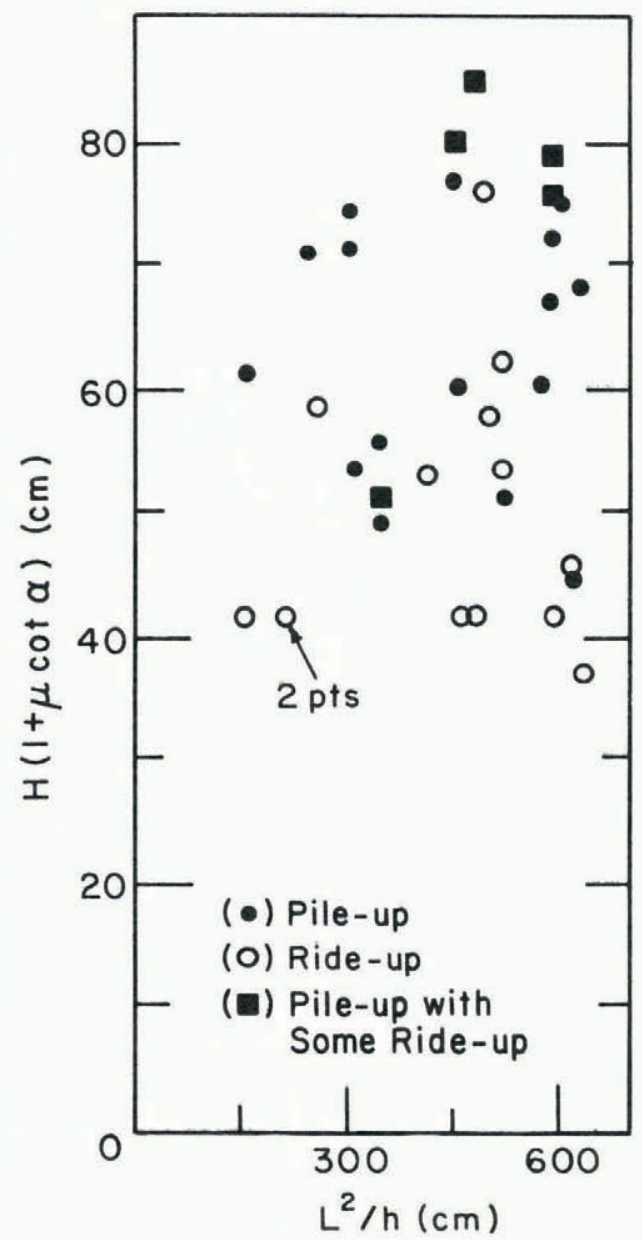

One can see in Figure 11 that the occurrences of ice pile-up and ride-up are grouped, and there is no such grouping in Figure 12. It should be warned that the number of data points are too few to draw any conclusions, and the results of this study should not be used in constructing prototypes. However, $\mathrm{H}(1-\mu \cot \alpha)$ appears to provide a group of parameters which can be correlated with the flexural properties of an ice sheet for identifying the occurrence of an ice pile-up or ride-up (Fig.11).

\section{SUMMARY}

Experiments were performed to observe ice pileups or ride-ups. The beach profiles were changed to vary the freeboard, slope and roughness of the beach. The occurrence of an ice pile-up or ride-up is reported as the final outcome of the experiment. The rough beach promoted ice pile-up earlier than the smooth beach.

The factors which govern the occurrence of an ice pile-up or ride-up are discussed.

\section{REFERENCES}

Abdelnour R, Edwards R Y Jr 1976 Model experiment to examine the behaviour of an ice field impinging on a man-made island. A[retic] P[etroleum] O[peratorg'] A[seciation] Report 109

Croasdale K R, Metge M, Verity P H 1978 Factors governing ice ride-up on sloping beaches. In IAHR. Intemational Association for Hydraulic Research. Symposium on ice problems, Lulea, Sweden, 1978. Proceedings Part 1: 405-420

Gladwell R W 1977 Ice conditions around artificial is lands 1975-76. A[retic] P[etroleum] O[peratorg'] A[s8ociation] Report 105-3

Haynes F D, Hirayama K, Kato K, Sodhi D S 1982 Friction tests on model ice. CRREL Intermal Report 744

Kovacs A, Sodhi D S 1980 Shore ice pile-up and rideup: field observations, models, theoretical analyses. Cold Regions Science and Technology 2: 209288

Semeniuk A 1977 Large scale interaction tests with an artificial island and with a caisson retained island, winter 1975-76. A[retic] P[etroleum] O[perators'] A[s8ociation] Report 103

Sodhi D S 1979 Buckling analysis of wedge-shaped floating ice sheets. In POAC 79: the fifth International Conference on Port and Ocean Engineering under Aretic Conditions, Trondheim, Norway, 1979. Proceedings Vol 1: 797-810

Vaudrey K D, Potter RE 1981 Ice defense for natural barrier islands during freezeup. In POAC 81: the sixth Intermational Conference on Port and ocean Engineering under Arctic Conditions, Québec, Canada, 1981. Proceedings Vol 1: 302-312

Fig.12. Plot of $H(1+\mu \cot \alpha)$ with respect to $L^{2} / h$. 